\title{
A SEXUALIDADE DA CRIANÇA
}

\author{
Maria Alves de Toledo Bruns ${ }^{1}$
}

\section{CHILD SEXUALITY}

Resumo: A perplexidade do adulto frente à expressão da sexualidade da criança se deve à histórica repressão sexual construída e perpetuada pelas instituiçōes no decorrer dos séculos. A psicanálise oferece um entre vários caminhos para se desvendar o complexo cenário psíquico que tem origem no imaginário familiar. Uma Educação Sexual contínua, voltada para a formação de profissionais da educação, da saúde e de áreas afins, pode, sem dúvida, favorecer a compreensão do adulto da expressão da sexualidade da criança.

Palavras-chave: Sexualidade da criança; repertório psíquico; educação familiar; mídia atual.

Abstract: The perplexity of an adult faced with the expression of a child's sexuality owes essentially to the historic sexual repression constructed and perpetuated by the institutions throughout the centuries. Psychoanalysis offers one among so many ways we can understand the complex psychic scenario, originated in the family imaginary. Continuous Sexual Education, aiming the qualification of professionals in education, health and related areas, may, undoubtedly, foster the adult's understanding of the expression of child sexuality.

Keywords: Child sexuality; psychic repertoire; family education; modern media. 
A sexualidade da criança? O que é isto? Criança é sexuada? Essa perplexidade se faz presente ainda nos dias atuais, não só entre pais e educadores, como também entre a maioria dos adultos. A descoberta do corpo pela criança, sua curiosidade para ver, tocar seus órgãos genitais, ou os dos pais, perguntas de como entrou na e saiu da barriga da mãe ainda desencadeiam mal-estar no adulto.

Ressalvando as exceções, a maioria dos adultos sente dificuldades diante de perguntas e cenas que expressam a curiosidade infantil sobre sexo. Diante de tal dificuldade, a criança foi e continua sendo vista por muitos como um ser assexuado, idealizada pela imagem de "anjo inocente". Essa dificuldade se justifica pelo lugar que a criança ocupou durante séculos na história da família e da sociedade ocidental. Com isto quero dizer que a representação de criança é nomeada, delineada e idealizada a partir dos modelos de família. Cabe, portanto, a cada unidade família, classe social e momento histórico engendrar de modo singular tabus, mitos, preconceitos, repressão sexual e segredos familiares. O que significa que o ethos familiar é historicamente construído e, portanto, é dinâmico e singular.

O modelo patriarcal possibilitava ao homem um lugar de destaque na hierarquia familiar. No centro do poder, cabia ao homem, protagonista dessa peça, executar o script, atuar na esfera pública e prover a família. Demonstração de afetos e sentimentos eram coisas de mulheres. Essas sim poderiam ser frágeis, dóceis, choronas ou frigidas, qualidades femininas exaltadas no desempenho bem sucedido do seu script: o qual a responsabilizava não apenas pela educação dos filhos, mas também pela harmonia do lar.

Exímia protagonista do modelo patriarcal, a mulher engendrava a mediação entre a voz dos filhos e a do pai. Cabia-lhe o direito de ocultar segredos ou de desvelar as diabruras deles. Quantas surras de chicotes as crianças desse modelo recebiam do pai, pela simples menção de suas diabruras relatadas pela mãe?! Assim, o distanciamento entre pai e filho(a) era estabelecido pelo medo, raiva, ódio, mágoa, desprezo e ameaças. O “tal respeito", tão clamado pelo modelo patriarcal, institui o distanciamento afetivo entre os familiares e a ausência de diálogo. E dificultou ao homem expressar seus afetos, suas emoções e a estabelecer o vínculo paternal.

Falar de si e expressar sentimentos? Como? Isso não os foi ensinado. A infância nesse modelo não era considerada um período especial da vida. $O$ pai detinha o poder, o saber e o direito de punir, reprimir e corrigir a criança para suprimir e controlar seus desejos. Disciplinava-lhe o corpo para evitar os possíveis desvios de comportamento. Os maus tratos físicos - de puxões de orelhas e 
beliscões a surras de cintos - somados às humilhações psicológicas eram os meios, as estratégias que garantiam aos pais dar uma "boa educação aos filhos".

Nessa dinâmica familiar os vínculos de asseguramento e pertencimento, tão importantes para a construção de uma estrutura psíquica que os capacitasse a enfrentar os desafios inerentes à vida, bem como lidar com a sexualidade de modo prazeroso, não eram levados em consideração.

A titulo de ilustração, uma passagem pelos séculos XVII e XVIII, focando a amamentação, por exemplo, oferece-nos uma explicação sobre como a relação mãe-filho viabilizava a internalização da disciplina do corpo. Nesses séculos, a amamentação da criança, que hoje sabemos ser tão necessária para a saúde do bebê quanto para fortalecer os vínculos afetivos entre mãe e bebê e vice-versa, era realizada por amas-de-leite - mulheres contratadas pelos pais, muitas sem nenhum preparo. Nessa época, os hábitos de higiene, indispensáveis à sobrevivência de bebês e crianças, não faziam parte dos procedimentos da maioria das amas-de-leite.

Era costume nessa época, também, enfaixar o bebê de modo a imobilizar seus braços e pernas. Outro aspecto que a literatura registra é que a morte de um filho não mobilizava a dor irreparável para a mãe como é experienciado nos dias de hoje. A perda de um filho era entendida como um acidente corriqueiro reparado por uma nova gravidez. Difícil para nós, pais dos dias atuais, compreendermos esses valores tão diferentes dos nossos!

Nos dizeres de Lins (1997, p. 94), “[...] Para Santo Agostinho, e durante longos séculos para a teologia cristã, foi dramática a imagem da infância. A criança era considerada o símbolo do pecado original nessa época”. Esse modelo priorizava a superioridade, autoridade e não a compreensão do pai, em relação ao lugar da criança e da mulher-esposa. A esta também não era permitido expressar ao homem-marido afetos e desejos sexuais. Demonstrá-los? Para quem não a ouvia e nem a sentia, isso não fazia sentido. Ao leitor interessado em compreender ou ampliar a compreensão desse momento histórico, Figueira (1986), Badinter (1985), Chauí (1984) Ariés (1981), entre outros autores, podem atender a tal intento.

Assim, esse conjunto de procedimentos sociais e institucionais, primordialmente repressores, é sutilmente internalizado pela estrutura psíquica da criança, que, de modo consciente ou inconsciente, decodifica os códigos de permissão, proibição, punição e os expressa em atos e ações no decorrer da sua existência, estando esses atos e ações em sintonia ou não com as normas e valores morais e sexuais de cada sociedade. 
Segundo André-Fustier \& Aubertel (1998, p.141): “[...] A censura familiar se organiza de tal modo a ser uma matriz de significaçóes, designando e situando a criança em um conjunto familiar e social".

Desse modo, a história da infância de cada pessoa desvela a um só tempo sua singularidade individual, a história de sua família, a classe social e sociedade da qual faz parte.

\section{Mudanças caminham lentamente...}

Mudanças econômicas, religiosas, políticas, científicas e tecnológicas ocorridas nos séculos XIX engendraram outros valores a maternagem, como nos diz Maldonado:

“[...] No século XIX, o culto à maternidade ampliou o lugar da mãe e da criança na sociedade. No século XX, especialmente com a psicanálise e de outras teorias psicológicas, reforçou-se a tendência de responsabilizar a mãe pelos problemas dos filhos" (Maldonado, 1989, p. 14).

Simultaneamente a essas descobertas científicas ocorreu a inserção da mulher no mercado de trabalho, que acelerou a flexibilização do paradigma do sistema patriarcal de tal modo que hoje, inicio do século XXI, encontramos um mosaico de famílias, entre outras modalidades as monoparentais, reconstruídas, adotivas, homossexuais e comunitárias. Conseqüentemente, o lugar da criança seja na esfera privada seja na esfera pública passou a ser redesenhado.

Nos dizeres de MacDougall (2000) é na infância que "as peças de nosso teatro interno" - os complexos cenários psíquicos - são originados. A infância retém os primeiros enredos de diferentes peças sobre as quais o "eu" representa seus dramas ocultos, roteiros e personagens que constituem nosso repertório psíquico. As primeiras cenas da história psicossexual de cada ser humano são edificados na infância, cenas que nos acompanharão por toda nossa existência. Na infância reside a importância singular que cada sociedade atribui ao seu projeto de ser humano.

A infância espelha o projeto que cada sociedade cria e recria no decorrer de sua história. Momento de construção de nossas subjetividades, marcadas pelos preconceitos, tabus, estigmas e/ou altruísmo, princípios solidários, etc. Isso sem falarmos das ressonâncias dos valores sexuais e estéticos presentes durante o nosso existir.

É preciso dizer que a descoberta desse teatro interno deve-se a Freud (1905/ 1997). Médico neurologista, considerado o pai da psicanálise, afirmou, há 
um século, que o ser humano desde criança é dotado de impulsos sexuais, ou seja, de libido - energia vital que se manifesta em todas as fases do desenvolvimento de nossa existência.

O corpo nessa perspectiva é dotado de zonas erógenas, entendidas como regiōes no corpo que, quando estimuladas, acariciadas, desencadeiam sensação de prazer qualitativamente diferente das demais regiōes do corpo quando tocadas. Assim, cada fase do desenvolvimento é caracterizada por uma zona erógena, ou seja, uma modalidade específica da organização da libido.

Isso não significa dizer que as demais regiōes do corpo não sejam passíveis de erotização. Como nos dizeres de Grandino \& Nogueira:

“[...] A fonte da sexualidade pode se localizar no corpo todo. Em qualquer lugar em que uma função orgânica se desenrole, incluindo a pele, os orifícios, os genitais e até os órgãos internos. Constrói-se um corpo erógeno sobreposto a um corpo biológico” (GRANDINO \& NOGUEIRA, 1987, p. 60)

Nessa trajetória de organização, três zonas erógenas caracterizam o desenvolvimento infantil. A fase oral é demarcada pelas sensações do prazer alimentar vivido durante a amamentação, momento em que mãe-bebê e/ou a pessoa responsável pelo bebê estabelece os vínculos de afetos imprescindíveis ao desenvolvimento saudável de futuras relações objetais.

A fase anal ocorre com a aprendizagem do controle esfincteriano. Para a criança, o valor simbólico das fezes - projeção e retenção - se dá por serem elas produzidas internamente pelo próprio corpo e pelo ritual do como expeli-las. Nesta fase, a qualidade da relação com a mãe e/ou adulto cuidador é que lhe possibilitará se estruturar psiquicamente para enfrentar as vicissitudes no decorrer da sua existência. Tomadas de decisão e capacidade para controlar sua vontade são dois dos aspectos fundamentais deste momento.

A fase fálica se constitui quando a erotização é focada nos genitais. A curiosidade e interesse da criança nesse momento se dirigem para as diferenças sexuais entre menino e menina e para a comparação e descoberta das diferenças entre o seu corpo e o corpo dos pais. A criança indaga se terá pêlos pubianos como os pais e porque a genitália dela é diferente da dos pais e/ou do(a) irmão/irmã.

Toques e manipulações das genitálias são comuns, como são também as preocupações dos pais com essas práticas. Nessa fase, o controle proibitivo do meio familiar e social estabelece os limites entre os impulsos agressivos 
e sexuais manifestado pela criança, que deseja manter maior aproximação com um dos pais - o do sexo oposto. Essa é a fase de triangulação a base do conflito edipiano. $\mathrm{O}$ menino expressa intenso amor pela mãe e o pai se coloca como o interceptor entre filho e mãe; ou seja, estabelece o limite da relação. Fantasias infantis de se casar e ou namorar a mãe são "vedadas pelo pai".

O desenrolar dessa peça configura-se pelo pai como o representante da lei, como interditor do incesto, levando o menino a reprimir a atração pela mãe. Angústia e sentimentos de culpa são originados pelos sentimentos ambivalentes de amor e ódio vividos pela criança em relação ao pai, inveja pelo tamanho do pênis, admiração pelo seu poder de decisão são algumas entre outras experiências do menino.

Segundo a psicanalista MacDougal:

"[...] Se, na vida do homem adulto, persistir a crença de que seu pênis é menor que deveria ser baseada na fantasia inconsciente de que o seu único sexo adequado é o paterno, precipitar-se-ão sintomas neuróticos e angústias, com a mesma freqüência com que estes ocorrem na vida sexual da mulher jovem, se esta se agarra inconscientemente à temível fantasia de ser um menino castrado" (Mcdouglas, 1997, p. 5)

Nos dizeres dessa autora, o menino é investido também de inveja e admiração pelo corpo da mãe e por sua sexualidade, postura similar à inveja e a admiração que a menina tem em relação ao pênis e às proezas sexuais do pai. Todavia, ambos atribuem à mãe um poder mágico de atrair o pênis do pai e de poder gerar bebês.

Para Winnicott:

"[...] A criança saudável torna-se capaz de ter sonhos plenamente genitais. $\mathrm{O}$ menino que toma o lugar do pai não pode evitar o confronto com: A idéia da morte do pai, portanto de sua própria morte; a da sua castração pelo pai, ou a castração do pai; de se tornar inteiramente responsável pela satisfação da mãe; e de um compromisso com o pai, numa linha que perpassa a homossexualidade. Nos sonhos das meninas, não podem ser evitadas: A idéia da morte da mãe e consequentemente a da sua própria morte; a de estar roubando da mãe o seu marido, seu pênis, seus filhos, e como resultado, a idéia de sua própria esterilidade; de ver-se à mercê da sexualidade do pai; e de um compromisso com a mãe numa linha que perpassa a homossexualidade" (WINNICOTT, 1990, p. 77)

A solução desses conflitos ocorre à medida que a criança consegue distinguir entre o que chamamos de realidade e fantasia. Ver os pais juntos ameniza a 
fantasia da morte deles. Para esse autor o fato da criança fantasiar que ocupa o lugar dos pais é a base, o alicerce para a resolução dos problemas referentes a ambivalência. A fantasia é a matéria-prima da socialização do individuo.

Considerando a complexidade que envolve a evolução psicossexual da criança, após a vivência dessas fases a criança entraria numa fase de latência, que se caracterizaria por focar os seus interesses nos aspectos sociais, escolares e esportivos, entre outros.

Após a vivência desse período, altamente questionado no momento atual devido à exposição da criança a estimulação e erotização veiculada pelos meios de comunicação - o corpo segue sua trajetória pela perpetuação da espécie e se lança ao chamado da vida que o engaja na descoberta dos prazeres das trocas eróticas, da elaboração de projetos e, assim, nesse processo de descobertas e de incertezas, as relações afetivo-sexuais acontecem. O medo, a insegurança, as curiosidades, os prazeres e os conflitos vividos nas fases anteriores são reeditados na adolescência.

Desse modo, a cada novo roteiro, os personagens, reeditam os enredos vividos na infância, os quais, por serem imantados de desejos originados no imaginário familiar, exercem função preponderante no modo de ser e de experimentar o mundo, bem como em relação a estruturação da personalidade e organização da identidade sexual. Afinal, nossa estrutura psíquica se organiza não apenas, mas também, pelo e no desejo do outro.

Dessa perspectiva, o desejo da mãe não é o único a exercer função determinante no funcionamento psíquico da criança, mas também os das demais pessoas (irmãos, irmãs, avós, entre outros) com que ela convive, que, segundo AndréFustier \& Aubertel (1998), exercem as funções de: - continência das angustias arcaicas correspondente à função de para-excitação, depositária de elementos simbióticos e sustentáculo das experiências do lactante; - transformação, corresponde ao trabalho psíquico assegurado pela dinâmica das relações familiares, que consiste em transformar as experiências sensórias do bebê em vivencias psíquicas; - ligação, tanto intrapsíquica quanto intersubjetiva, que possibilita o bebê, com base nas vivências psíquicas, se auto-conter e organizar sua própria psique e estabelecer relações objetais no decorrer da existência.

Assim, indago como a dinâmica familiar atual, demarcada pelos descasamentos, casamentos sucessivos, parcerias estáveis e/ou não, vem atuando como matriz de sentidos e significados para a criança se estruturar como 
ser sexuado e assim chegar a vivenciar a adolescência sem os fantasmas de uma gravidez e ou da paternidade indesejável, bem como da AIDS e DST. O que a família, a escola e os meios de comunicação vêm (ou não vêm) proporcionando às crianças?

Ressalvando as exceções, muitos pais preferem ignorar as manifestaçōes da sexualidade expressa pelas crianças, acreditando que são inocentes. Outros ainda acham que se conversarem sobre "esses assuntos" com as crianças, podem estar incentivando-as ao inicio da atividade sexual, e por fim, há uma grande parcela de pais que se sentem despreparados para lidar com as questôes pertinentes a sexualidade.

No que diz respeito à escola, esta, em geral, promove palestras sobre DST e AIDS somente para os adolescentes. Em geral, o professor não se sente preparado para estabelecer um diálogo sobre os interesses, dúvidas e curiosidades da criança. Desse modo, a escola não promove espaço para a reflexão e os diálogos tão necessários para a ocorrência de esclarecimentos e fortalecimentos de vínculos afetivos e emocionais entre educador e a criança.

Nesse contexto, os meios de comunicação representam importante papel na divulgação de assuntos ligados à sexualidade. Pode-se, sem dificuldade, detectar uma superestimulação precoce da sexualidade por meio de programas em que há uma excessiva exposição do corpo, pela veiculação de filmes e cenas erótico-pornográficas e também pela banalização da sexualidade. Isso sem falarmos da nocividade da vulgarização da violência, tão presente na mídia. Urge dizer que esta realidade vem sendo lentamente questionada pelos pais, pelos profissionais da saúde e educação e ainda por aqueles profissionais que se percebem co-responsáveis pelos programas veiculados pela mídia.

Mais do que considerar este um problema "dos outros", questionar e denunciar o lugar que a mídia ocupa no momento atual é dever de cada um de nós. Assim, faz-se necessário: rever e recriar valores que visualizem a criança a partir do ethos dos fatores sociopolítico, econômico e cultural, que ressoam de modo singular nas unidades familiares, bem como da interferência dos imperativos e apelos da mídia nas reorganizações psíquica.

Urge dizer que essa caótica realidade poderia ser amenizada se houvesse uma política de Educação Sexual contínua, voltada para a formação de profissionais da educação, da saúde e de áreas afins, uma vez que todos têm profunda influência na formação das crianças e dos adolescentes. 


\section{Referências bibliográficas}

ANDRÉ-FUSTIER, F. \& AUBERTEL, F. A transmissão psíquica familiar pelo sofrimento. In: KASËS, FAIMBERG A transmissão psíquica entre gerações: enfoque em terapia familiar psicanalítica. São Paulo: Unimarco Editora, 1998.129-179.

ÁRIES, P. História social da criança e da família. Rio de Janeiro: Nova Fronteira, 1981.

BADINTER, E. Um amor conquistado: o mito do amor materno. Rio de Janeiro: Nova Fronteira, 1985.

CHAUÍ, M. Repressão sexual: Essa nossa (des)conhecida. São Paulo: Ed. Brasiliense, 1984.

FIGUEIRA, S. Uma nova família brasileira? O "moderno" e o "arcaico" na nova família brasileira de classe média. Rio de Janeiro: Jorge Zahar Ed, 1986.

FREUD, S.(1905) Três ensaios sobre a teoria da sexualidade. Rio de janeiro: Imago Ed. 1997.

GRANDINO, A. \& NOGUEIRA, D. Sexo ou Sexualidade: A visão da psicanálise. Porto Alegre: L\& PM, 1987. (Coleção Universidade Livre)

LINS, R. N. A cama na varanda: arejando nossas idéias a respeito de amor

e sexo. Rio de Janeiro: Rocco, 1997.

MALDONADO, M. T. Maternidade e paternidade. Petrópolis: Vozes, 1989.

MacDOUGAL, J. Teatros do Corpo: o psicossoma em psicanálise. São Paulo: Martins Fontes, 2000.

As múltiplas faces de Eros: Uma exploração psicanalítica da sexualidade humana São Paulo: Martins Fontes, 1997.

WINNICOTT, D.W. Natureza Humana. Rio de Janeiro: Imago Ed., 1990. 